\title{
philosophy of structures
}




\section{by Eduardo Torroja}

\section{English Version by J. J. Polivka}

and Milos Polivka

1967

University of California Press

Berkeley and Los Angeles 


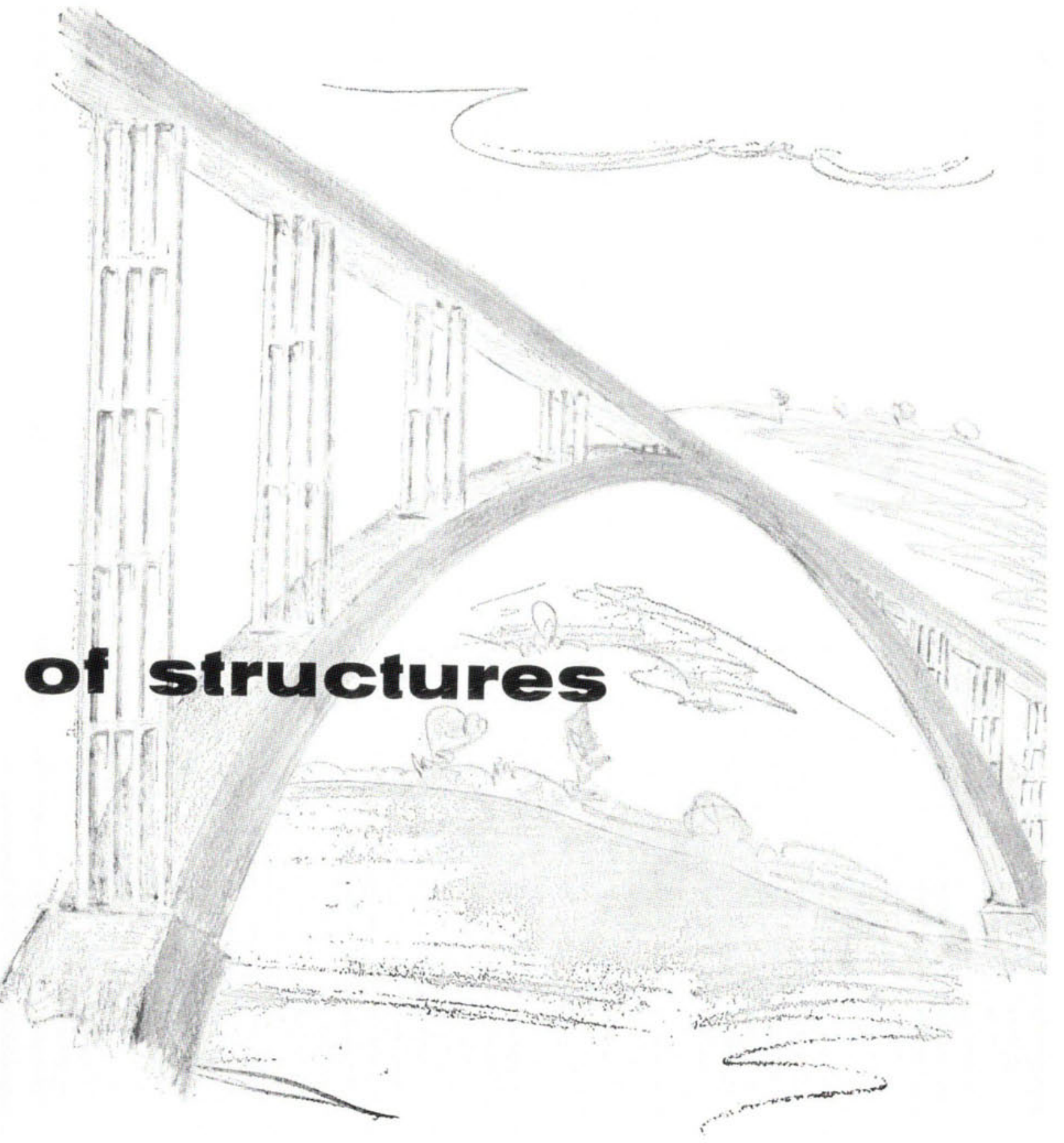


University of California Press

Berkeley and Los Angeles, California

Cambridge University Press

London, England

(C) 1958 by The Regents of the University of California

Third Printing, 1967

Library of Congress Catalog Card Number: $58-6523$

Designed by John B. Goetz

Manufactured in the United States of America 